\title{
Some for All Rather Than More for Some: $A$ Myth or a Reality?
}

\section{Gourisankar Ghosh}

\begin{abstract}
1 Introduction
It is now more than 20 years since the New Delhi consultation was held under the theme of 'Some for All Rather than More for Some'. More than a dozen major conferences have been held since, besides numerous resolutions agreed at different United Nations and other inter-governmental forums. A key question is whether the theme 'Some for All' is still relevant and why opposition from powerful quarters may have led the subsequent Dublin Statement to get more push than the New Delhi Statement? This perspective looks in more detail at this critical theme for the water sector, including addressing the suggestion made over the years that New Delhi and Dublin are somehow at odds.
\end{abstract}

The UN Water Decade (1980-90) was a wonderful experience of collaboration among UN agencies and governments, with many experimental projects resulting at the community level. One of the most successful private-public partnerships was to successfully implement the new research and development of hand pumps and other equipment for exploration, testing and maintenance of the water infrastructure. The United Nations Development Programme (UNDP), UNICEF and the World Bank worked together towards the success of these initiatives in Africa and Asia.

The idea of having an end of the Water Decade consultation for sharing experiences and to prepare future steps came to me while attending a Latin American conference in Recife, Brazil. I immediately discussed the idea with David Grey and Saul Arlosoroff of the World Bank, Frank Hartvelt of UNDP and Martin Bayer of UNICEF, and the result was the New Delhi conference.
New Delhi was the natural venue for such a consultation, but it took time to convince the different departments of the Government of India. Martin Bayer went on secondment to UNDP to head the conference international secretariat and I headed the national secretariat. As we planned the consultation together, we agreed that the event should have a theme, and 'Some for All Rather than More for Some' was developed by David Grey and me.

The Government of India at higher levels became very excited with the process, as did the UN agencies. I was elected chair of the drafting committee and we worked throughout the night to draft what became the New Delhi Statement (United Nations 1990), primarily through utilising the skills of Brian Appleton and David Grey. Within three months, the General Assembly of the United Nations endorsed the statement!

\section{Why the theme?}

Water is key to rural development. The fight against poverty will not be won without equitable and just water distribution. Land reform alone has failed in many places to establish development for the poor in the absence of more equitable distribution of water and universal access to the resource for rural agricultural and drinking purposes. Our trigger for the slogan 'Some for All' was the alarming push to privatise water resources and their distribution without developing a more equitable model.

Unfortunately, this was misunderstood as a slogan for free water, although nowhere in the New Delhi Statement was such a proposal mooted. 


\section{The reasons for opposition}

A section of water specialists in UN agencies as well as in the World Bank believed that water in developing countries provided a perfect market and that the blind application of economic tools like pricing, and full cost recovery, was the only solution to the sustainability of services. While there was not much difference of opinion on the recovery of operation and maintenance costs, a 'full' recovery including the cost of the resource or (for privatisation) in order to 'protect' the resources was never a valid argument. Besides, the Decade had recognised that issues like gender, community participation, ownership, participation, and communication were as important as the choice of technology or cost recovery.

This new paradigm threatened the traditionalists who wanted to find only a hardware solution to the problem. Resource management using economic tools was the common model as implemented in urban water supply. The timing was therefore crucial, shunting the Decade's efforts aside and giving way to a shift in focus on simple economic issues and tools. The fact that agriculture consumes more than 75 per cent of water resources and a small increase in efficiency can provide crucial water needed for the domestic sector was, until recently, never seriously addressed.

It should also be remembered that the New Delhi Statement aimed to provide guiding principles for the 1990s. The 1990s, however, became a decade of meetings, unnecessary debate and non action, in many ways pushing the water movement backwards. Every important donor or UN agency wanted to have a programme of their own, and coordination and partnership as undertaken in the Water Decade was lost to a great extent. More in ideas and action was contributed by institutes such as in the private domain Pacific Institute.

In this article, I will revisit the four guiding principles as laid out in the New Delhi Statement. These guiding principles remain relevant today:

- Protection of the environment and safeguarding of health through the integrated management of water resources and liquid and solid wastes;

- Institutional reforms promoting an integrated approach and including changes in procedures, attitudes and behaviour, and the full participation of women at all levels in sector institutions;

- Community management of services, backed by measures to strengthen local institutions in implementing and sustaining water and sanitation programmes;

- Sound financial practices, achieved through better management of existing assets, and widespread use of appropriate technologies.

The New Delhi Statement was the first to mention and endorse Integrated Water Resources Management and tried to sketch out a plan for an integrated approach not only for the domestic sector but in other sectors too. It was a pioneer of wastewater management and possibly recognised for the first time the importance of hygiene issues. It was, however, deliberately weak on sanitation and did not offer a good platform for establishing a strong private sector role. In fact, the different roles of agencies were left poorly defined, perhaps encouraging confusion in responsibilities. Nonetheless, the New Delhi Statement was endorsed by the General Assembly of the United Nations in December 1990 and remained the official consensus and roadmap of that institution. For this reason it is important to compare these principles with those enumerated in Dublin two years later in 1992.

\section{Dublin Principles}

In principle there should not be any conflict between the New Delhi Statement (United Nations 1990) and the Dublin Principles (United Nations 1992) as Dublin was encompassing the entire water management spectrum within the broader objective of sustainable development. The first three principles were more general in nature. In fact, the New Delhi Statement was more direct and action oriented. Dublin states:

- Principle No 1: Fresh water is finite and vulnerable.

- Principle No 2: Water development and management should be based on a participatory approach.

- Principle No 3: Women play a central part in the provision, management and safeguarding of water.

- Principle No 4: Water has an economic value in all its competing uses and should be recognised as an economic good. Within this principle, it is vital to recognise first the basic right of all human beings to have access to clean water and sanitation at an affordable price. 
In fact, there should not be any conflict at all between these two principles, except that the phrase water 'as an economic good' was propagated without any context and without reference to the rest of the statements in Principle No 4.

In 1995, UNICEF, in its first water policy, combined the New Delhi and Dublin Statements. While it did not mention water as an economic good it certainly endorsed access at an affordable price. It has to be left to the governments to decide how to ensure water and sanitation facilities reach the vulnerable populations. In recent years, the World Bank and others have also agreed that economic tools alone cannot help ensure sustainable development. Though some claim that the Dublin Principles gave birth to Integrated Water Resources Management (IWRM), basically, the thought process began in New Delhi. However, a good model has not been found yet at country level which integrates harmoniously agriculture, drinking water and industrial use, all under one water resources department.

\section{What next?}

I argue that the slogan and theme of New Delhi remains valid. It basically addresses consumption control, judicious use of water, and equitable distribution or access for the population. Recent work on water footprinting and sincere attempts to reduce water consumption in agriculture show that the concept is not only still valid but has

\section{References}

United Nations (1992) The Dublin Statement on Water and Sustainable Development, International Conference on Water and the Environment, Dublin, 31 January 1992, www.ielrc.org/content/ e9209.pdf (accessed 1 December 2011) been refined further. Nevertheless, a number of questions remain unanswered, where further research will be required.

How to ensure equitable distribution in urban consumption? How can communities protect precious water supplies from upstream pollution? How judiciously can economic tools be used by the communities themselves? I would argue further that the frequently used phrase of 'water security' is a version of the 'Some for All' philosophy. Protection of river basins will be a major challenge to achieve some for all!

The role and contribution of the private sector will be extremely important now and in the future. Various models around the world have shown that the private sector can play a major role in new technical innovations, skills development and the planning, execution, operation and maintenance of projects and the protection of water bodies. Proper regulatory models and institutions will be needed and possibly with popular participation from civil society. The private sector should really try to be a partner in all facets of a project, especially in bringing in reform and skills development, and not merely finance alone.

Only 'Some for All' will reduce costs, save the resources both physical and financial, and bring the communities towards sustainable development. The New Delhi Statement and its theme are still alive.

\section{United Nations (1990) New Delhi Statement, Global Consultation on Safe Water and Sanitation, 1990, www.ielrc.org/content/e9005.pdf (accessed} 1 December 2011) 